\title{
Mild decrease in heart rate during early phase of targeted temperature management following tachycardia on admission is associated with unfavorable neurological outcomes after severe traumatic brain injury: a post hoc analysis of a multicenter randomized controlled trial
}

\author{
Akihiko Inoue ${ }^{1,2+}$, Toru Hifumi ${ }^{1,3^{*}+}$ (D), Yasuhiro Kuroda ${ }^{1}$, Naoki Nishimoto ${ }^{4}$, Kenya Kawakita ${ }^{1}$, Susumu Yamashita ${ }^{5}$, \\ Yasutaka Oda ${ }^{6}$, Kenji Dohi ${ }^{7}$, Hitoshi Kobata ${ }^{8}$, Eiichi Suehiro ${ }^{6}$, Tsuyoshi Maekawa ${ }^{9}$ and on behalf of the Brain \\ Hypothermia (B-HYPO) Study Group in Japan
}

\begin{abstract}
Background: The association between isolated admission heart rate (HR) and prognosis has been discussed, but not that between gross HR change and neurological outcome in patients with severe traumatic brain injury (TBI). In the acute phase of severe TBI, HR is influenced by several factors (e.g., pain, sympathetic activation, hypovolemia, fever, body temperature). Therefore, admission HR and gross HR change should be examined in patients with TBI treated with a well-designed protocol, such as was done in the Brain Hypothermia (B-HYPO) Study.

Methods: This was a post hoc analysis of the B-HYPO Study, which was conducted as a prospective, multicenter, randomized controlled trial in patients with severe TBI receiving mild therapeutic hypothermia $\left(\mathrm{MTH} ; 32.0^{\circ} \mathrm{C}-34.0^{\circ} \mathrm{C}\right)$ or fever control $\left(35.5^{\circ} \mathrm{C}-37.0^{\circ} \mathrm{C}\right)$ in Japan. Patients with $\mathrm{MTH}$ were examined, and HR change $(\% \mathrm{HR})$ in the early MTH phase was calculated as follows: [admission HR - HR at day 1]/admission HR $\times 100$. Patients were divided into six groups, using admission HR $(<80,80-99, \leq 100)$ and median of \%HR; i.e., group (Admission $H R<80$ and \%HR $\geq 18.6$ ); group (Admission $H R<80$ and \%HR < 18.6); group (Admission HR 80-99 and \%HR $\geq 18.6$ ); group (Admission HR 80-99 and \%HR < 18.6); group (Admission HR $\geq 100$ and \%HR $\geq 18.6$ ); and group (Admission $H R \geq 100$ and $\% H R<18.6$ ). The primary outcome was an adjusted predicted probability of unfavorable neurological outcome at 6 months after TBI according to Glasgow Outcome Scale score, which is a measure of functional recovery and defined as severe disability, persistent vegetative state, and death.

(Continued on next page)
\end{abstract}

\footnotetext{
* Correspondence: hifumitoru@gmail.com

${ }^{+}$Akihiko Inoue and Toru Hifumi contributed equally to this work.

${ }^{1}$ Department of Emergency, Disaster and Critical Care Medicine, Kagawa

University Hospital, 1750-1 Ikenobe, Miki, Kita, Kagawa 761-0793, Japan

${ }^{3}$ Emergency and Critical Care Medicine, St. Luke's International Hospital, 9-1

Akashi-cho, Chuo-ku, Tokyo 104-8560, Japan

Full list of author information is available at the end of the article
}

(c) The Author(s). 2018 Open Access This article is distributed under the terms of the Creative Commons Attribution 4.0 International License (http://creativecommons.org/licenses/by/4.0/), which permits unrestricted use, distribution, and reproduction in any medium, provided you give appropriate credit to the original author(s) and the source, provide a link to the Creative Commons license, and indicate if changes were made. The Creative Commons Public Domain Dedication waiver (http://creativecommons.org/publicdomain/zero/1.0/) applies to the data made available in this article, unless otherwise stated. 
(Continued from previous page)

Results: Overall, 79 patients with MTH (52.7\% of the original trial) were examined; among these, unfavorable neurological outcomes were observed in 53.2\%. Among all the groups, group (Admission HR $\geq 100$ and \%HR < 18.6) exhibited the highest proportion of unfavorable outcomes, and $82.3 \%$ of patients had an adjusted predicted probability of unfavorable outcomes, whereas those in group (Admission HR $<80$ and \%HR $\geq 18.6$ ) developed only 22.8\% ( $p=0.04)$.

Conclusions: Mild HR decrease during the early phase of targeted temperature management following tachycardia at admission can be associated with unfavorable neurological outcomes after severe TBI.

Keywords: Traumatic brain injury, Admission heart rate, Heart rate change, Targeted temperature management, Neurological outcomes

\section{Background}

Several studies have reported the association between bradycardia during targeted temperature management (TTM) and good neurological outcome in comatose survivors of out-of-hospital cardiac arrest (OHCA) [1-3]. Therefore, attention has been focused on the association between heart rate (HR)/HR change during TTM and neurological outcome in neurocritical care.

HR has been discussed as an autonomic dysfunction in patients with severe traumatic brain injury (TBI). An association between isolated admission HR and prognosis has been discussed $[4,5]$, as has the association between exposure to beta-blockers and mortality in patients with TBI, but the studies did not focus on HR change [6, 7]. Recently, $\mathrm{HR}$ variability (i.e., tiny $\mathrm{HR}$ change) has been reported to be associated with increased mortality after TBI [8]. Therefore, the association between gross HR change during the early phase of TTM and neurological outcomes in patients with severe TBI must be examined.

In the acute phase of severe TBI, HR is influenced by several factors, such as pain [9], sympathetic activation [10], hypovolemia caused by massive bleeding from other injured sites [11], fever [12], and body temperature [13]. Therefore, admission HR and HR change should be examined in patients with severe TBI treated with a well-designed protocol in which sedation, analgesia, target body temperature, blood volume, and treatment of injured organs were well controlled. We describe the association between HR change during the early phase of TTM and unfavorable neurological outcomes in patients with severe TBI using data from the Brain Hypothermia (B-HYPO) Study Group, in which the primary outcome was Glasgow Outcome Scale (GOS) score at 6 months [14].

\section{Methods}

\section{B-HYPO Study}

The B-HYPO Study was conducted as a prospective, multicenter, randomized controlled trial (RCT) between December 2002 and September 2008 in Japan. The protocol was approved by the institutional review board of each participating hospital, and the trial was registered at the University Hospital Medical Information Network site (UMIN-CTR no. C000000231) in Japan and at the National Institutes of Health site (ClinicalTrials.gov identifier NCT00134472) in the United States. In brief, inclusion criteria were age 15 to 69 years for both sexes and a Glasgow Coma Scale (GCS) score of 4 to 8 measured upon arrival at the hospital. Written informed consent was obtained from legally authorized representatives of patients before inclusion. If informed consent could not be obtained within $2 \mathrm{~h}$ of admission, the consent policy was waived.

\section{Patients}

In the original study, 150 patients were assigned randomly (1:2 allocation ratio) to either the fever control $\left(35.5^{\circ} \mathrm{C}-37.0^{\circ} \mathrm{C}\right)$ or mild therapeutic hypothermia $(\mathrm{MTH})$ group $\left(32.0^{\circ} \mathrm{C}-34.0^{\circ} \mathrm{C}\right)$, and they were analyzed by intention-to-treat analysis [14]. Per-protocol analysis was performed in 135 patients (Fig. 1) (fever control, 47 patients; MTH, 88 patients) [15]. In the present post hoc study, we described data of these patients with MTH $(n=88)$ on the basis of HR change between admission and day 1 .

\section{Targeted temperature management}

Treatments were performed as described in our original study [14]. In brief, cooling was initiated within $2 \mathrm{~h}$ of the onset of TBI. Cooling blankets, rapid cold fluid infusion (up to $1000 \mathrm{ml}$ of saline, human plasma products, or dextrose-free plasma expanders), and/or cold gastric lavage were used during the induction phase in both groups. The goal in each group was to achieve the targeted temperature within $6 \mathrm{~h}$ of the onset of TBI and to maintain this temperature for at least $72 \mathrm{~h}$, predominantly using surface cooling blankets. After $72 \mathrm{~h}$, the temperature was maintained at $<38{ }^{\circ} \mathrm{C}$ until 7 days after the onset of TBI.

\section{Sedation and hemodynamic management}

The sedation protocol specified either midazolam (0.2$0.4 \mathrm{mg} / \mathrm{kg} / \mathrm{h}$ ) and nonnarcotic analgesics or neuroleptic 


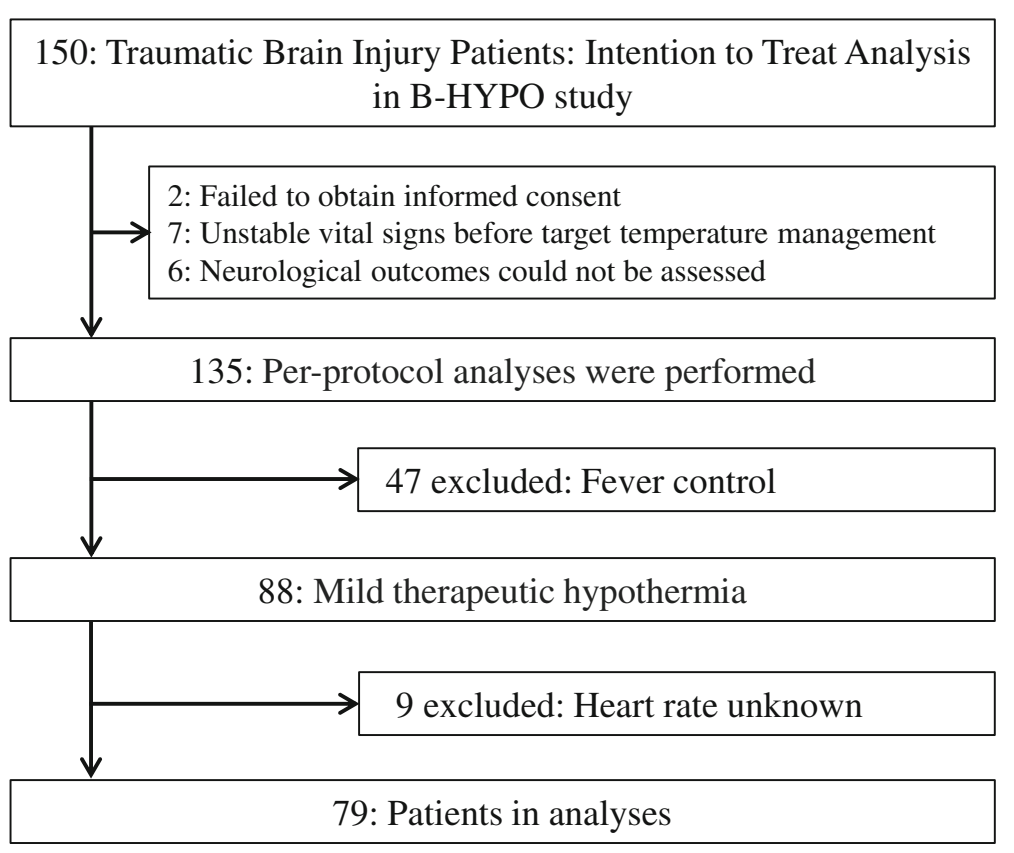

Fig. 1 Patient flow

analgesia $(25 \mu \mathrm{g} / \mathrm{kg} / \mathrm{h}$ droperidol and $1 \mu \mathrm{g} / \mathrm{kg} / \mathrm{h}$ fentanyl). Sedatives and analgesics were usually tapered once the patients had been rewarmed to $36^{\circ} \mathrm{C}$. Neuromuscular blockade, including vecuronium $(0.05 \mathrm{mg} / \mathrm{kg} / \mathrm{h})$ or pancuronium $(0.05 \mathrm{mg} / \mathrm{kg} / \mathrm{h})$, was used during induction and maintenance phases as necessary. Shivering, if it developed, was evaluated and managed according to the criteria of each facility.

Hemodynamic status was monitored and maintained strictly, using an arterial catheter, pulmonary arterial catheter, and intracranial pressure (ICP) monitoring probe to monitor hemodynamic status and ICP at the following levels: mean arterial pressure $>80 \mathrm{mmHg}$, cardiac index $>2.5 \mathrm{~L} / \mathrm{min} / \mathrm{m}^{2}$, systemic vascular resistance index 800 to $1200 \mathrm{dyn} / \mathrm{s} / \mathrm{cm}^{5}$, ICP $<20 \mathrm{mmHg}$, and cerebral perfusion pressure $>60 \mathrm{mmHg}$.

\section{Data collection and study outcomes}

Data on the following parameters were collected: age, sex, HR, blood pressure, GCS score, unreactive pupil or pupils on admission, Traumatic Coma Data Bank computed tomography classification [16], surgical intervention for TBI during admission, ICP, Injury Severity Score (ISS), Abbreviated Injury Scale score for the head, blood glucose, TTM (MTH or fever control), and unfavorable neurological outcomes at 6 months following TBI. MTH was achieved at a median of $8.1 \mathrm{~h}$ (IQR, 5.3-11.8 h) [14]. HR was measured at admission (Admission HR) and on day 1 (median time, $23.4 \mathrm{~h}$ after admission).

\section{Primary exposure}

HR change (\%HR) between Admission HR and HR at early stage of TTM $(23.4 \mathrm{~h}, 17.4-28.7 \mathrm{~h}$, in the B-HYPO Study) was calculated as $(\% \mathrm{HR}=$ [admission $\mathrm{HR}-\mathrm{HR}$ at day 1$] /$ admission $H R \times 100$ ). Because the HR change (admission $\mathrm{HR}-\mathrm{HR}$ at day 1 ) is considerably influenced by admission $H R$, we used \%HR instead of $\Delta H R$ to measure HR change. A positive value shows a decrease in $H R$, whereas a negative value shows an increase in HR from admission to day 1. That is, a larger \%HR corresponds with a moderate decrease, whereas a smaller \%HR corresponds with a mild decrease in HR from admission to day 1.

A previous study examining the association between admission HR and mortality in patients with moderate to severe TBI reported a smooth U-shaped relationship between admission HR and mortality, with the lowest mortality in patients with HR 80 to 99. Therefore, we used three cutoff values for admission HR $(<80,80-99, \leq 100)$ [4]. With regard to $\% \mathrm{HR}$, we used the median of \%HR 18.6 because there were no previous studies examining the HR change in patients with TBI. Thus, to describe the association between admission $\mathrm{HR}$ or \% $\mathrm{HR}$ and unfavorable neurological outcomes, study patients were divided into six groups using the admission HR $(<80,80-99, \leq 100)$ and median \%HR (median, 18.6; IQR, - 8.6 to 32.5): group (Admission $\mathrm{HR}<$ 80 and $\% \mathrm{HR} \geq 18.6$ ), group (Admission $\mathrm{HR}<80$ and $\% \mathrm{HR}$ $<18.6$ ), group (Admission $\mathrm{HR} 80-99$ and $\% \mathrm{HR} \geq 18.6$ ), group (Admission HR 80-99 and \%HR < 18.6), group (Admission $\mathrm{HR} \geq 100$ and $\% \mathrm{HR} \geq 18.6$ ), and group (Admission $\mathrm{HR} \geq 100$ and $\% \mathrm{HR}<18.6$ ). 


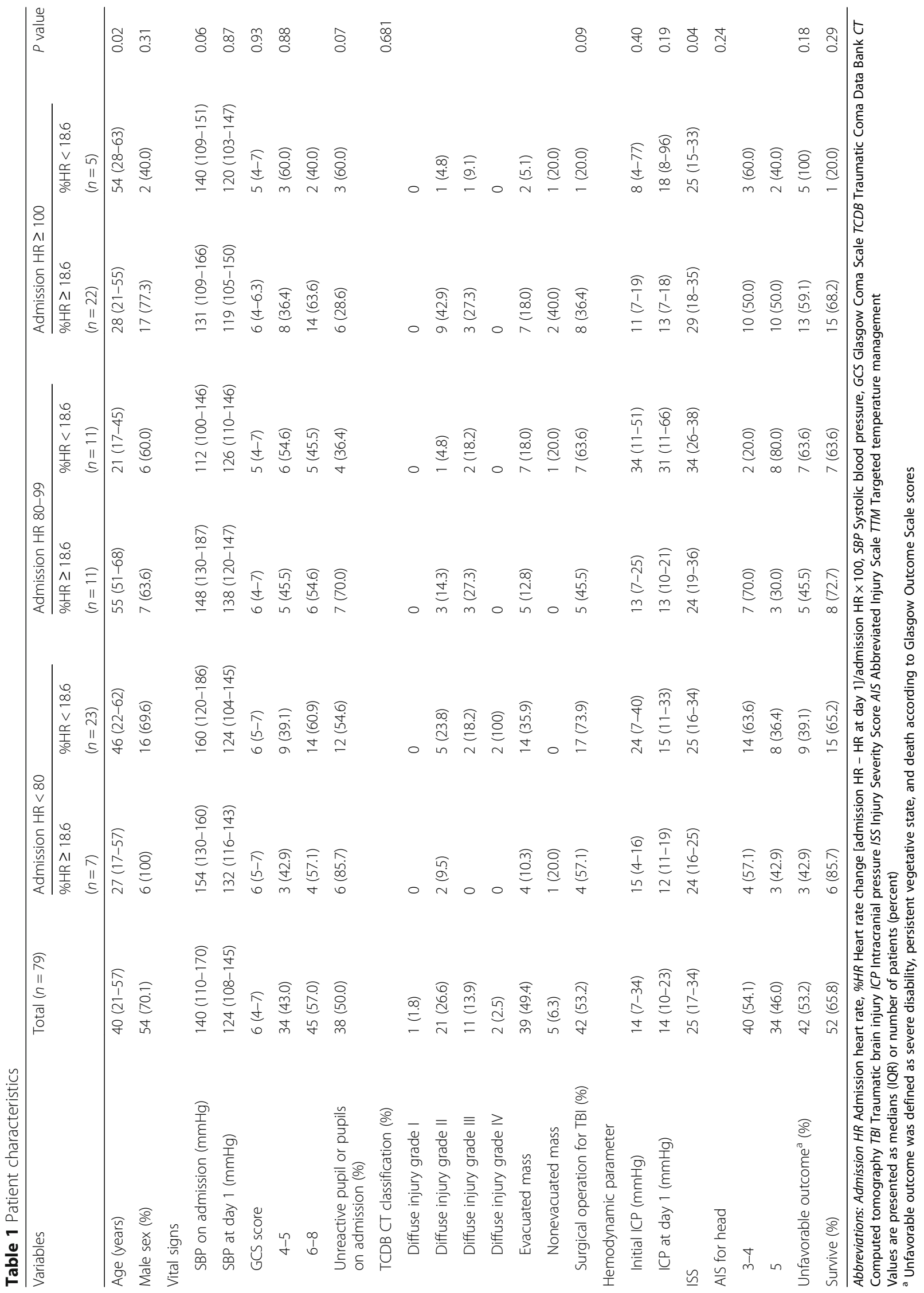




\section{Study endpoints}

Primary outcome was an adjusted predicted probability of unfavorable neurological outcome at 6 months after TBI, where an unfavorable outcome was defined as severe disability, persistent vegetative state, and death, according to the GOS score, which is a measure of functional recovery.

\section{Statistical analyses}

To compare baseline characteristics, study participants were divided into six groups using the primary exposure. Next, because of the small number of patients included in the present study, instead of performing multiple analyses to examine whether HR change (i.e., in the six groups) could be an independent predictor of unfavorable outcome, we used the multiple logistic regression models adjusting for age [17-19], sex [20], GCS score $[17,21,22]$, unreactive pupil on admission [23], surgical intervention for TBI during admission [24], ICP [25] at day 1 , and ISS $[17,22]$ to obtain adjusted predicted probabilities of unfavorable outcome in the six different groups using the admission HR and median \%HR; therefore, six HR change groups were not included in the analyses as adjusting factors.

Continuous variables were analyzed using the Mann-Whitney $U$ test or Kruskal-Wallis test, and categorical comparisons were performed using the $x^{2}$ or Fisher's exact test, when appropriate. Statistical analysis was performed using JMP version 12 statistical software (SAS Institute, Inc., Cary, NC, USA). Results are presented as $n$ (\%) or median (IQR). $P<0.05$ was considered statistically significant.

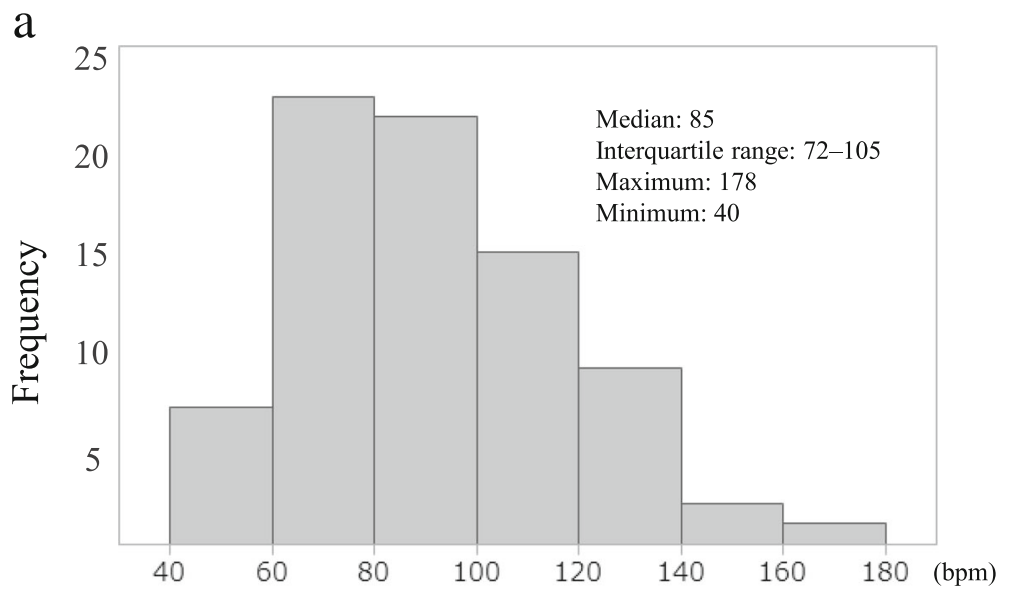

Admission heart rate

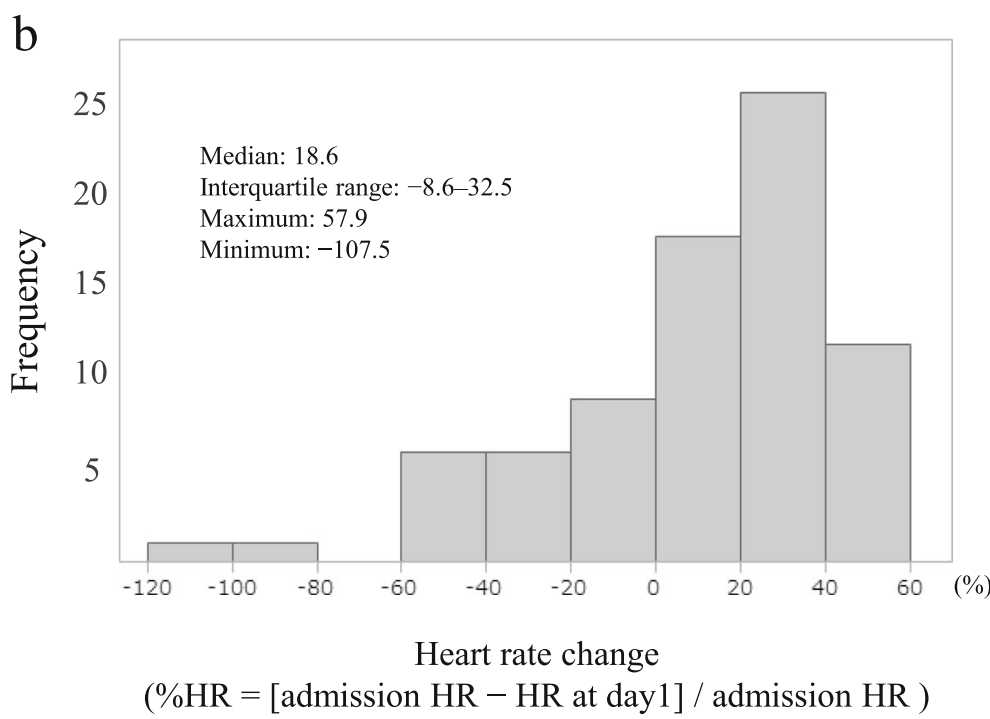

Fig. 2 a Distribution of admission heart rate. $\mathbf{b}$ Distribution of heart rate change. Bpm Beats/min, HR Heart rate 


\section{Results}

A total of nine patients were excluded owing to having an unavailable admission $\mathrm{HR}$ or day $1 \mathrm{HR}$. The remaining 79 patients (median age 40.0 years, 70.1\% male) were analyzed (Fig. 1). Unfavorable neurological outcomes and survival rates at 6 months were $53.2 \%$ and $65.8 \%$, respectively, and $28.8 \%$ (15/52) of actual survivors had an unfavorable outcome. The median GCS score was 6 (4-7), and median ISS was 25 (17-34) (Table 1). The median Admission HR was 85 beats/min [bpm] (72-105), and median \%HR was 18.6 ( -8.6 to 32.5$)$. The distribution of these data is shown in Fig. 2a and b. The proportions for unfavorable outcome were $40.0 \%, 54.5 \%$, and $66.7 \%$ in patients with Admission HR $<80 \mathrm{bpm}$, Admission HR 80-99 bpm, and Admission HR $\geq 100$ bpm, respectively (Fig. 3). The baseline characteristics were significant differences in age and ISS (Table 1). Other detailed data of baseline characteristics were divided into six groups using primary exposure and are shown in Additional file 1: Table S1. There were significant differences in blood glucose at day 1 , stress index at

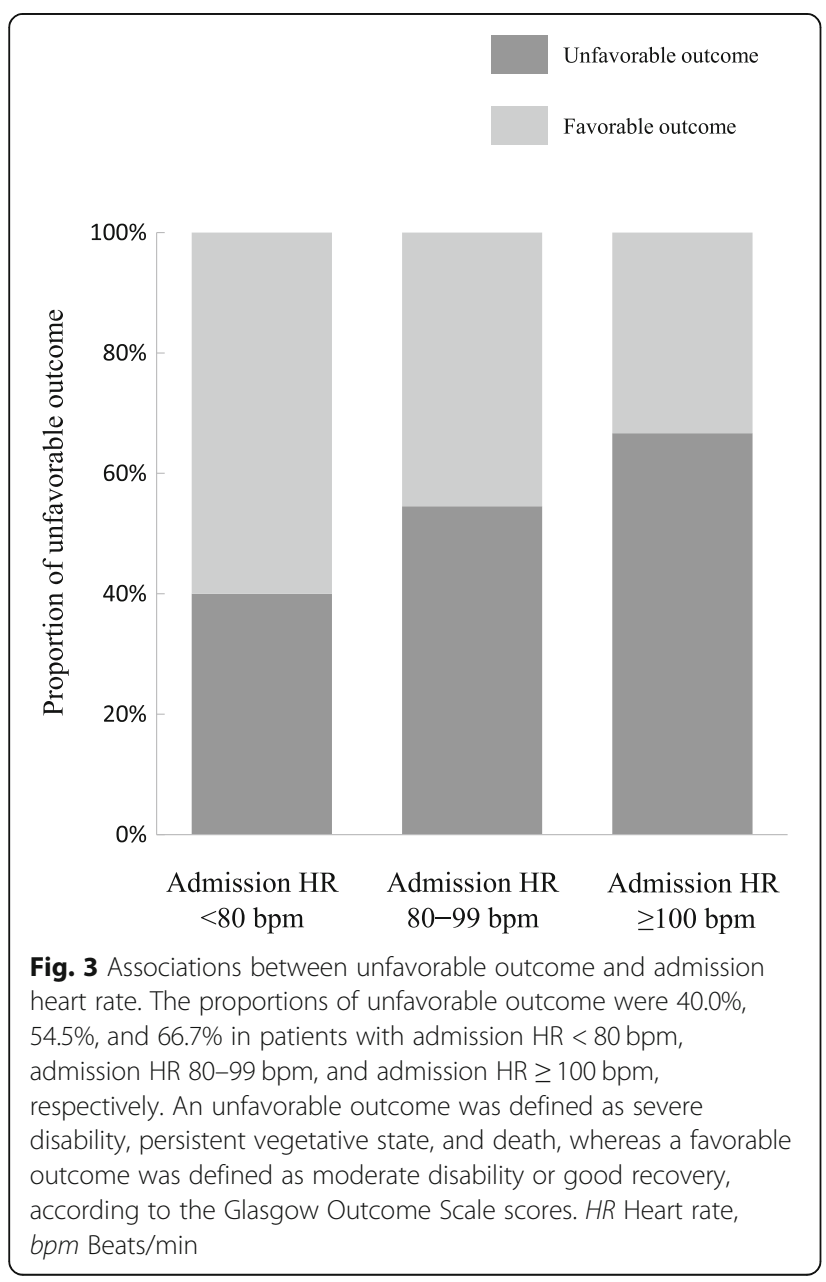

day 1 , and pulmonary arterial wedge pressure at day 1. Comparison of patient characteristics between the unfavorable and favorable outcome groups showed significant differences in age (Additional file 1: Table S2). Fever control patients $(n=47)$ were excluded from the present study. A comparison of patient characteristics between the MTH and fever control groups is shown in Additional file 1: Table S3.

\section{Association between \%HR and unfavorable neurological outcomes}

Regarding the primary endpoint, group (Admission $\mathrm{HR} \geq$ 100 and \%HR $<18.6)$ had the highest proportion $(100 \%)$ of unfavorable outcomes among the six groups (Table 1). The adjusted predicted probabilities of unfavorable outcome were $22.8 \%, 45.6 \%, 57.0 \%, 60.7 \%, 53.4 \%$, and $82.3 \%$ in group (Admission $\mathrm{HR}<80$ and $\% \mathrm{HR} \geq 18.6$ ), group (Admission $\mathrm{HR}<80$ and $\% \mathrm{HR}<18.6$ ), group (Admission HR 80-99 and $\% \mathrm{HR} \geq 18.6$ ), group (Admission $\mathrm{HR} 80-99$ and $\% \mathrm{HR}<18.6$ ), group (Admission $H R \geq 100$ and $\% H R \geq 18.6$ ), and group (Admission $\mathrm{HR} \geq 100$ and \%HR < 18.6), respectively (Fig. 4).

\section{Discussion}

In the present post hoc study, unfavorable neurological outcomes occurred in 53.2\% (42 of 79) patients with severe TBI. Group (Admission HR $\geq 100$ and \%HR < 18.6) had the highest proportion of unfavorable outcomes, and $82.3 \%$ of those patients had an adjusted predicted probability of unfavorable outcome, whereas group (Admission HR $<80$ and $\% H R \geq 18.6$ ) developed only $22.8 \%$. In the present study, we limited the patients to only those in the MTH group because the difference in targeted temperature may cause strong heterogeneity in HR change.

Two previous studies demonstrated the association between isolated admission HR and mortality $[4,5]$. A smooth U-shaped relationship was observed between admission HR and mortality, with the lowest mortality in patients with HR 80 to $89[4,5]$. In the present study, patients with an Admission $\mathrm{HR} \geq 100 \mathrm{bpm}$ followed by \%HR $<18.6$ during initiation of TTM demonstrated an $82.3 \%$ adjusted predicted probability of an unfavorable outcome, whereas patients with \%HR $\geq 18.6$ in those patients had an approximately $50 \%$ of predicted probability of an unfavorable outcome. These facts suggested that tachycardia at admission followed by mild decrease in HR during the early phase of TTM could be another candidate for predicting unfavorable neurological outcomes.

During MTH, it has been well discussed that the suppression of HR was caused by suppression of spontaneous depolarization of cardiac pacemaker cells, prolongation of the duration of action potentials, slowing of myocardial impulse conduction [13], indirect suppression of sympathetic activity [26-28], and activation of parasympathetic activity [28]. Sympathetic activation also is an important factor in 


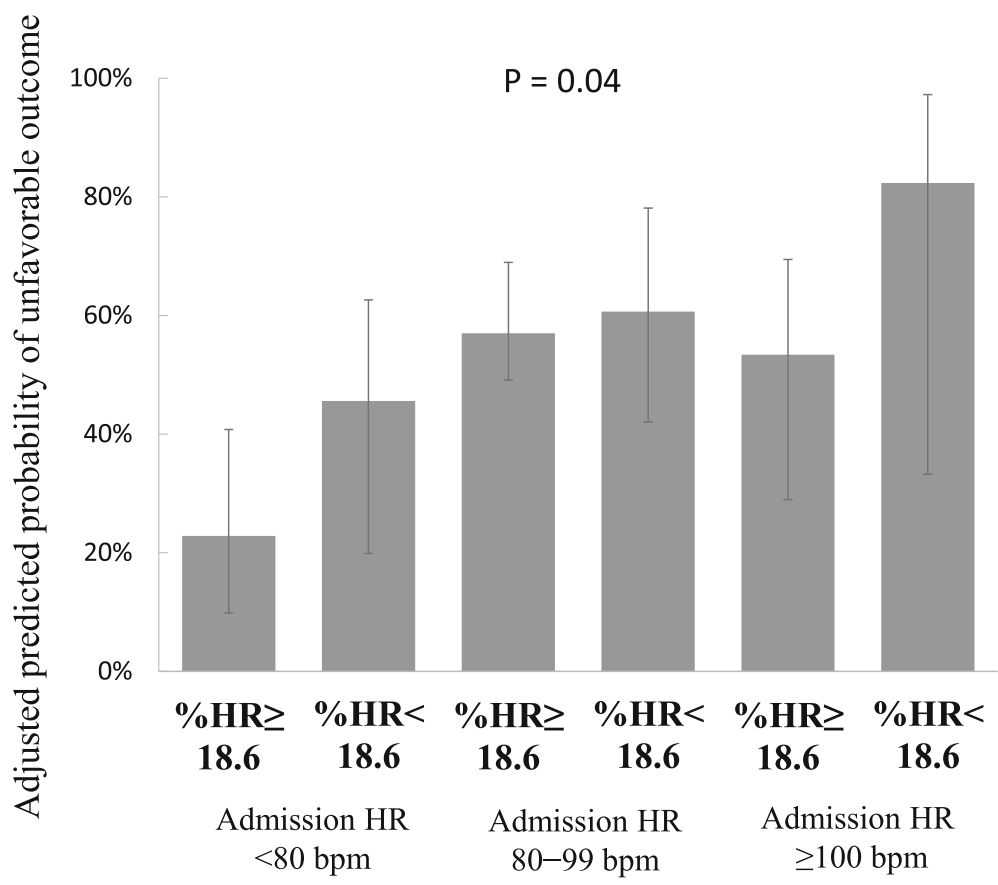

Fig. 4 The adjusted predicted probability of unfavorable outcome for \%HR groups. The median adjusted predicted probabilities of unfavorable outcome were 22.8\%, 45.6\%, 57.0\%, 60.7\%, 53.4\%, and 82.3\% in group (Admission HR < 80 and \%HR $\geq 18.6$ ), group (Admission HR $<80$ and \%HR < 18.6), group (Admission HR 80-99 and \%HR $\geq 18.6$ ), group (Admission HR 80-99 and \%HR < 18.6), group (Admission HR $\geq 100$ and \%HR $\geq 18.6$ ), and group (Admission HR $\geq 100$ and \%HR < 18.6), respectively. HR Heart rate, \%HR Heart rate change ([admission HR - HR at day 1]/admission $H R \times 100)$, bpm Beats/min. Error bars indicate the IQR

\%HR during TTM. We suspected that Admission $\mathrm{HR} \geq$ $100 \mathrm{bpm}$ reflected sympathetic activation, high plasma catecholamine level, and severity of primary damage in patients with TBI. The reduction of $\% \mathrm{HR}$ reflected the reduction of plasma catecholamine levels in patients whose Admission HR had increased to $\geq 100 \mathrm{bpm}$ [29]. Therefore, we considered that patients with tachycardia on admission followed by mild decrease in HR during early-phase TTM had a high incidence of unfavorable outcomes.

Many RCTs have been conducted to investigate the effectiveness of MTH for TBI, but they could not demonstrate more favorable outcomes than those obtained by normothermia (at $37^{\circ} \mathrm{C}$ ) [14, 30-32]. However, the latest guidelines from an expert panel suggest considering TTM at $35^{\circ} \mathrm{C}-37^{\circ} \mathrm{C}$ to improve survival with good neurological outcome in patients with severe TBI, and also considering TTM at $34^{\circ} \mathrm{C}-35^{\circ} \mathrm{C}$ to lower ICP in patients with TBI with refractory intracranial hypertension despite medical treatments [33]. Thus, TTM (mild hypothermia and fever control) should be considered in patients with severe TBI. In such situations, withdrawal of intensive care always should be considered after initial TTM, because recent guidelines on OHCA primarily address the termination of resuscitative efforts during performance of TTM [34, 35]. Appropriate determination of factors predicting neurological outcomes also may contribute to reduce healthcare- associated costs. According to our results, all patients in group (Admission $\mathrm{HR} \geq 100 \mathrm{bpm}$ and $\% \mathrm{HR}<18.6$ ) had unfavorable outcomes.

There are several limitations to our study. First, the original study was terminated before the full sample size was reached. Additionally, the sample size was reduced further from 150 to 79 patients because HR could not be obtained in 9 to 88 patients. These factors may have biased the outcomes of our study. Second, confounders of $\mathrm{HR}$ response, such as the use of preinjury beta-blockers [1, 36, 37], vasopressor support, amount of bleeding and fluids, and urine volume, were not examined, owing to unavailability of the dataset. However, hemodynamic status was monitored and maintained based strictly on the study protocol. Third, the number of patients included in the present study was small. Furthermore, we divided included patients into six groups using the admission HR $(<80,80-99, \leq 100)$ and median \%HR (median 18.6), which might have caused complexity. Finally, selection bias may have been present.

\section{Conclusions}

Mild decrease in HR during initiation of TTM following an initially increased HR can be associated with unfavorable neurological outcomes after severe TBI. 


\section{Additional file}

Additional file 1: Table S1. Patient characteristics. Table S2.

Comparison of patient characteristics between unfavorable and favorable outcomes. Table S3. Comparison of patient characteristics between the mild therapeutic hypothermia and fever control groups. (DOCX $44 \mathrm{~kb}$ )

\section{Abbreviations}

AIS: Abbreviated Injury Scale; B-HYPO Study: Brain Hypothermia Study; CT: Computed tomography; GCS: Glasgow Coma Scale; GOS: Glasgow Outcome Scale; HR: Heart rate; ICP: Intracranial pressure; ISS: Injury Severity Score; MTH: Mild therapeutic hypothermia; OHCA: Out-of-hospital cardiac arrest; RCT: Randomized controlled trial; TBI: Traumatic brain injury; TCDB: Traumatic Coma Data Bank; TTM: Targeted temperature management

\section{Acknowledgements}

None.

\section{Funding}

This study was supported by research project grants from the Japanese Ministry of Health, Labor and Welfare (H-14-shinkin-005, H-15-shinkin-001, and $\mathrm{H}$-16-shinkin-001) and by the Japanese Human Science Association, 2002-2004.

\section{Availability of data and materials}

Please contact the authors for data requests.

\section{Authors' contributions}

$\mathrm{Al}$ and $\mathrm{TH}$ were responsible for conception of the article and drafted and revised the manuscript. NN helped to conduct statistical analyses and to revise the manuscript. YK helped to create the study design and draft the manuscript. KK, SY, YO, KD, HK, ES, and TM helped to draft the manuscript. All authors read and approved the final manuscript and take full responsibility for all aspects of the study.

\section{Ethics approval and consent to participate}

The protocol and consent procedures were approved by the institutional review board of each participating hospital.

\section{Consent for publication}

Not applicable.

\section{Competing interests}

The authors declare that they have no competing interests.

\section{Publisher's Note}

Springer Nature remains neutral with regard to jurisdictional claims in published maps and institutional affiliations.

\section{Author details}

${ }^{1}$ Department of Emergency, Disaster and Critical Care Medicine, Kagawa University Hospital, 1750-1 Ikenobe, Miki, Kita, Kagawa 761-0793, Japan. 2Department of Emergency and Critical Care Medicine, Hyogo Emergency Medical Center, 1-3-1 Wakinohamakaigandori, Chuo-ku, Kobe, Hyogo 651-0073, Japan. ${ }^{3}$ Emergency and Critical Care Medicine, St. Luke's International Hospital, 9-1 Akashi-cho, Chuo-ku, Tokyo 104-8560, Japan. ${ }^{4}$ Clinical Research and Medical Innovation Center, Hokkaido University Hospital, Kita 14, Nishi 5, Kita-ku, Sapporo, Hokkaido 060-8648, Japan. ${ }^{5}$ Department of Emergency Medicine, Tokuyama Central Hospital, 1-1 Kouda, Shunan, Yamaguchi 745-8522, Japan. ${ }^{6}$ Advanced Medical Emergency and Critical Care Center, Yamaguchi University School of Medicine, 1-1-1 Minami Kogushi, Ube, Yamaguchi 755-8505, Japan. Department of Emergency, Disaster and Critical Care Medicine, Showa University, 1-5-8 Hatanodai, Shinagawa-ku, Tokyo 142-8555, Japan. ${ }^{8}$ Osaka Mishima Emergency Critical Care Center, 11-1 Minamiakutagawacho, Takatsuki, Osaka 569-1124, Japan. ${ }^{9}$ Yamaguchi Prefectural University, 3-2-1 Sakurabatake, Yamaguchi City, Yamaguchi 753-8502, Japan.
Received: 11 May 2018 Accepted: 26 November 2018

Published online: 19 December 2018

\section{References}

1. Thomsen JH, Nielsen N, Hassager C, Wanscher M, Pehrson S, Kober L, et al. Bradycardia during targeted temperature management: an early marker of lower mortality and favorable neurologic outcome in comatose out-ofhospital cardiac arrest patients. Crit Care Med. 2016;44(2):308-18.

2. Staer-Jensen $H$, Sunde $K$, Olasveengen TM, Jacobsen D, Draegni T, Nakstad ER, et al. Bradycardia during therapeutic hypothermia is associated with good neurologic outcome in comatose survivors of out-of-hospital cardiac arrest. Crit Care Med. 2014;42(11):2401-8.

3. Inoue A, Hifumi T, Yonemoto N, Kuroda Y, Kawakita K, Sawano H, et al. The impact of heart rate response during 48-hour rewarming phase of therapeutic hypothermia on neurologic outcomes in out-of-hospital cardiac arrest patients. Crit Care Med. 2018;46(9):e881-8.

4. Ley EJ, Berry C, Mirocha J, Salim A. Mortality is reduced for heart rate 80 to 89 after traumatic brain injury. J Surg Res. 2010;163(1):142-5.

5. Ley EJ, Singer MB, Clond MA, Ley HC, Mirocha J, Bukur M, et al. Admission heart rate is a predictor of mortality. J Trauma Acute Care Surg. 2012;72(4): 943-7.

6. Ko A, Harada MY, Barmparas G, Thomsen GM, Alban RF, Bloom MB, et al. Early propranolol after traumatic brain injury is associated with lower mortality. J Trauma Acute Care Surg. 2016:80(4):637-42.

7. Umemura T, Nakamura Y, Nishida T, Hoshino K, Ishikura H. Fibrinogen and base excess levels as predictive markers of the need for massive blood transfusion after blunt trauma. Surg Today. 2016;46(7):774-9.

8. Sykora M, Czosnyka M, Liu X, Donnelly J, Nasr N, Diedler J, et al. Autonomic impairment in severe traumatic brain injury: a multimodal neuromonitoring study. Crit Care Med. 2016:44(6):1173-81.

9. Hilgard ER, Morgan AH, Lange AF, Lenox JR, MacDonald H, Marshall GD, et al. Heart rate changes in pain and hypnosis. Psychophysiology. 1974;11(6): 692-702.

10. Hortnagl H, Hammerle AF, Hackl JM, Brucke T, Rumpl E, Hortnagl H. The activity of the sympathetic nervous system following severe head injury. Intensive Care Med. 1980;6(3):169-7.

11. Gutierrez G, Reines HD, Wulf-Gutierrez ME. Clinical review: Hemorrhagic shock. Crit Care. 2004;8(5):373-81.

12. Davies $P$, Maconochie I. The relationship between body temperature, heart rate and respiratory rate in children. Emerg Med J. 2009;26(9):641-3.

13. Polderman $\mathrm{KH}$. Mechanisms of action, physiological effects, and complications of hypothermia. Crit Care Med. 2009;37(7 Suppl):S186-202.

14. Maekawa T, Yamashita S, Nagao S, Hayashi N, Ohashi Y. Prolonged mild therapeutic hypothermia versus fever control with tight hemodynamic monitoring and slow rewarming in patients with severe traumatic brain injury: a randomized controlled trial. J Neurotrauma. 2015;32(7):422-9.

15. Hifumi T, Kuroda Y, Kawakita K, Yamashita S, Oda Y, Dohi K, et al. Fever control management is preferable to mild therapeutic hypothermia in traumatic brain injury patients with Abbreviated Injury Scale 3-4: a multicenter, randomized controlled trial. J Neurotrauma. 2016;33(11):1047-53.

16. Marshall LF, Marshall SB, Klauber MR, van Berkum Clark M, Eisenberg HM, Jane JA, et al. A new classification of head injury based on computerized tomography. J Neurosurg. 1991;75(1 Suppl):S14-20.

17. Baum J, Entezami P, Shah K, Medhkour A. Predictors of outcomes in traumatic brain injury. World Neurosurg. 2016;90(Supplement C):525-9.

18. Martins ET, Linhares MN, Sousa DS, Schroeder HK, Meinerz J, Rigo LA, et al. Mortality in severe traumatic brain injury: a multivariated analysis of 748 Brazilian patients from Florianopolis City. J Trauma. 2009;67(1):85-90.

19. Hukkelhoven CW, Steyerberg EW, Rampen AJ, Farace E, Habbema JD, Marshall LF, et al. Patient age and outcome following severe traumatic brain injury: an analysis of 5600 patients. J Neurosurg. 2003;99(4):666-73.

20. Bazarian JJ, Blyth B, Mookerjee S, He H, McDermott MP. Sex differences in outcome after mild traumatic brain injury. J Neurotrauma. 2010;27(3):527-39.

21. Timmons SD, Bee T, Webb S, Diaz-Arrastia RR, Hesdorffer D. Using the Abbreviated Injury Severity and Glasgow Coma Scale scores to predict 2week mortality after traumatic brain injury. J Trauma. 2011;71(5):1172-8.

22. Foreman BP, Caesar RR, Parks J, Madden C, Gentilello LM, Shafi S, et al. Usefulness of the Abbreviated Injury Score and the Injury Severity Score in comparison to the Glasgow Coma Scale in predicting outcome after traumatic brain injury. J Trauma. 2007;62(4):946-50. 
23. Marmarou A, Lu J, Butcher I, McHugh GS, Murray GD, Steyerberg EW, et al. Prognostic value of the Glasgow Coma Scale and pupil reactivity in traumatic brain injury assessed pre-hospital and on enrollment: an IMPACT analysis. J Neurotrauma. 2007:24(2):270-80

24. Hartings JA, Vidgeon S, Strong AJ, Zacko C, Vagal A, Andaluz N, et al. Surgical management of traumatic brain injury: a comparative-effectiveness study of 2 centers. J Neurosurg. 2014;120(2):434-46.

25. Sorrentino E, Diedler J, Kasprowicz M, Budohoski KP, Haubrich C, Smielewski $\mathrm{P}$, et al. Critical thresholds for cerebrovascular reactivity after traumatic brain injury. Neurocrit Care. 2012;16(2):258-66.

26. Tokunaga S, Imaizumi T, Fukae K, Nakashima A, Hisahara M, Tominaga R, et al. Effects of hypothermia during cardiopulmonary bypass and circulatory arrest on sympathetic nerve activity in rabbits. Cardiovasc Res. 1996;31(5): 769-76.

27. Park KS, Choi JK, Park YS. Cardiovascular regulation during water immersion. Appl Hum Sci. 1999;18(6):233-41.

28. Mourot L, Bouhaddi M, Gandelin E, Cappelle S, Dumoulin G, Wolf JP, et al. Cardiovascular autonomic control during short-term thermoneutral and cool head-out immersion. Aviat Space Environ Med. 2008;79(1):14-20.

29. Muengtaweepongsa S, Jantanukul A, Suwanprasert K. Should the heart rate including the heart rate variability be important prognosticators in cardiac arrest? Resuscitation. 2016;98:e15.

30. Clifton GL, Valadka A, Zygun D, Coffey CS, Drever P, Fourwinds S, et al. Very early hypothermia induction in patients with severe brain injury (the National Acute Brain Injury Study: Hypothermia II): a randomised trial. Lancet Neurol. 2011:10(2):131-9.

31. Hutchison JS, Ward RE, Lacroix J, Hebert PC, Barnes MA, Bohn DJ, et al. Hypothermia therapy after traumatic brain injury in children. N Engl I Med. 2008;358(23):2447-56.

32. Clifton GL, Miller ER, Choi SC, Levin HS, McCauley S, Smith KR Jr, et al. Lack of effect of induction of hypothermia after acute brain injury. N Engl J Med. 2001;344(8):556-63.

33. Cariou A, Payen JF, Asehnoune K, Audibert G, Botte A, Brissaud O et al. Targeted temperature management in the ICU: guidelines from a French expert panel. Anaesthesia Crit Care Pain Med. 2018;37(5):481-91.

34. Callaway CW, Donnino MW, Fink EL, Geocadin RG, Golan E, Kern KB, et al. Part 8: Post-cardiac arrest care: 2015 American Heart Association quidelines update for cardiopulmonary resuscitation and emergency cardiovascular care. Circulation. 2015;132(18 Suppl 2):S465-82.

35. Nolan JP, Soar J, Cariou A, Cronberg T, Moulaert VR, Deakin CD, et al. European Resuscitation Council and European Society of Intensive Care Medicine guidelines for post-resuscitation care 2015: section 5 of the European Resuscitation Council guidelines for resuscitation 2015. Resuscitation. 2015(95):202-22

36. Bascom K, Riker RR, Seder DB. Heart rate and the post cardiac arrest syndrome: another clue to individualizing care? Crit Care Med. 2016;44(2):448-9.

37. Aibiki M. Can bradycardia during therapeutic hypothermia help predicting neurologic outcome and be beneficial in post-cardiac arrest patients? Crit Care Med. 2015;43(3):e97.

Ready to submit your research? Choose BMC and benefit from:

- fast, convenient online submission

- thorough peer review by experienced researchers in your field

- rapid publication on acceptance

- support for research data, including large and complex data types

- gold Open Access which fosters wider collaboration and increased citations

- maximum visibility for your research: over $100 \mathrm{M}$ website views per year

At $\mathrm{BMC}$, research is always in progress.

Learn more biomedcentral.com/submissions 